\title{
LECTURA DE UN SISTEMA TEXTUAL. LOS CUENTOS DE AUGUSTO ROA BASTOS*
}

\author{
En varios sitios a la vez surge a peda- \\ zos la historia del viejo que nos está \\ mirando con su burlona mirada de muerto. \\ De modo que, una vez más, la voluntad \\ de la palabra cumple el milagro de dar siete \\ vueltas a la vida de un hombre, de matarlo \\ y resucitarlo muchas veces. . .
}

La frase con la que el narrador de "Cuerpo presente"' se refiere al cuento y recuento de la vida de Chepé Bolívar puede considerarse como una descripción, apenas metafórica, de la organización general de la narrativa de Roa Bastos. En efecto, uno de los caracteres más evidentes en el caso de este escritor es, por una parte, el retorno, en el interior de un mismo libro, de personajes y situaciones que remiten de un cuento a otro; por otra, la reproposición, en cada uno de sus libros, de cuentos ya publicados en los libros anteriores: es como si El trueno entre las hojas (1953) y $E l$ baldio (1966) - que se presentan como conjuntos independientes - afloraran y se entremezclaran en Los pies sobre el agua (1967) y en Madera quemada (1967), hasta llegar a Moriencia (1969), en donde los dos últimos son absorbidos (véase el apéndice).

Puede atribuirse esta republicación a razones de orden meramente editorial, pero creo que es posible ir más allá, y considerarla como un modo particular de repensar la propia producción, de sugerir connotaciones diferentes. El hecho puede servirnos, por lo tanto, como punto de partida para reflexionar sobre un problema más general: el de la redefinición del sentido de un cuento,

- Un anticipo de este trabajo fue presentado en el "Coloquio Internacional Augusto Roa Bastos, cuentista", Universidad de Poitiers, 7-9 de diciembre de 1983.

${ }^{1}$ En Moriencia, Monte Ávila, Caracas, 1969, p. 49. 
según el sentido global del conjunto del que pasa a formar parte.

Desde este punto de vista, resulta sumamente útil el concepto de macrotexto propuesto por María Corti. Para ella, algunos conjuntos de textos (cuentos, poemas) pueden presentarse como simple suma de elementos, en la que cada texto conserva un valor aislado, sin colocarse en un esquema general de lectura. En otros conjuntos, en cambio, cada texto, aunque completo y autosuficiente, remite a un paradigma en el que se sitúa de modo preciso, y el efecto de la lectura total no es el de simple suma de textos autónomos, sino el de creación de una estructura que los redefine como texto unitario, o sea, como un macrotexto. Esta segunda posibilidad se reconoce por la presencia de dos rasgos: una combinatoria de elementos temáticos y/o formales, que se actualiza en la organización de todos los textos; y una progresión del discurso por la cual cada texto sólo puede encontrarse en el lugar en el que se encuentra ${ }^{2}$.

Éste parecería ser el caso de Roa Bastos en Hijo de hombre (1960), por ejemplo, que se presenta como una novela pero que, como ya ha notado la crítica, está formado por una serie de relatos independientes. En los otros casos, dada la publicación de los mismos cuentos en distintos libros, y con una colocación diferente cada vez, debería negarse al libro el carácter de macrotexto, pues no cumpliría con el requisito de la progresión del discurso.

Creo, sin embargo, que las opciones no son tan nítidas, y que existen conjuntos que, si bien no se configuran estrictamente como macrotextos, tampoco resultan una suma de elementos aislados, sino que definen un sistema textual. Este sistema textual se organiza según ejes identificables en la totalidad de los textos de un conjunto, y que permiten actualizar, para cada cuento, virtualidades distintas, según el conjunto en el que estén colocados ${ }^{3}$.

${ }^{2}$ M. CORTI, “ ¿Testi o macrotesto? I racconti di Marcovaldo di Italo Calvino", Strumenti Critici, 1975, núm. 27. Véase también Principi della comunicazione letteraria, Bompiani, Milan, 1976, cap. 4.

${ }^{3}$ Estos ejes unificadores del conjunto corresponden al concepto de isotopía de un texto formulado por Greimas: "...par isotopie nous entendons un ensemble redondant de catégories sémantiques qui rend possible la lecture uniforme du récit, telle qu'elle résulte des lectures partielles des énoncés après résolution de leurs ambigüités, cette résolution elle-même étant guidée par la recherche de la lecture unique" (A.-J. GREIMAS, "Éléments pour une théorie du récit mythique", en Communications, 1966, núm. 8, p. 30). Más amplia la visión de F. RASTIER, quien toma también en consideración, para la constitución de las isotopías, los niveles formales del texto ("Systématique des isotopies", en A.-J. GREIMAS, ed., Essais de sémiotique poétique, Larousse, Paris, 1971) 
Aquí intentaré identificar esos ejes de acuerdo con los cuales se constituye, a partir de desplazamientos y reiteraciones, el sistema de los cuentos de Roa Bastos en cada conjunto; intentaré responder, en cierta medida por lo menos, a la pregunta inevitable que como lectores nos planteamos: ¿considerar cada conjunto donde los cuentos se repiten una antología o, ya que no se trata de una repetición pura y simple sino de una inclusión en el interior de materiales nuevos, releerlos - repensarlos - en un nuevo sistema? Sistema que, de todos modos, no se cierra en sí mismo sino que remite a un sistema textual más vasto, el de la totalidad de la narrativa de Roa Bastos, extraordinariamente homogénea en su espacio, su tiempo, sus actores, sus temas y sus técnicas.

La constitución de un sistema es obviamente resultado de la lectura entendida como proceso memorial, que reintegra los signos aislados y los pone en relación de orden y de sentido ${ }^{4}$. En el caso de Roa Bastos, la lectura de cada texto da por sí sola cuenta de un microcosmos, de una totalidad significante. La lectura de todos los textos que forman un conjunto los coloca, sin embargo, como definiciones parciales de una misma realidad, y lo mismo puede decirse de la síntesis superior que resulta de la lectura de todos los conjuntos.

Desde El trueno entre las hojas se hace evidente la homogeneidad del espacio ${ }^{5}$. Se trata de un mundo rural, a duras penas ganado a la selva, inclemente por exceso o por carencia. La constante referencia extratextual (Tebikuary del Guayrá, San Juan de Borja en "Carpincheros", Paraguarí en "Mano Cruel", Villa Encarnación en "El ojo de la muerte", Asunción en "Regreso", etc.) coloca este espacio, sin vacilaciones, en el mapa de Paraguay, por lo que aun los lugares no nombrados pueden situarse de modo coherente con el resto. En la producción siguiente, este espacio se amplía, pero siempre dentro de un mismo esquema: los espacios nuevos tienen las mismas características y función que los precedentes. Así por ejemplo, a partir de El baldio, al aludir en el primer cuento ("El baldío") al "olor del agua estancada del Ria-

${ }^{4}$ Sobre el proceso de lectura como síntesis memorial, véanse las interesantes consideraciones de C. SEGRE, La strutture e il tempo, Einaudi, Torino, 1974, pp. 15-19.

${ }^{5}$ Sobre las características del sistema espacio-temporal en Roa Bastos, un detallado estudio se encuentra en A. L. ALDANA, La cuentística de Augusto Roa Bastos, Géminis, Montevideo, 1975, pp. 52-64. Son también de interés las observaciones de carácter descriptivo sobre la recurrencia de hechos y personajes (pp. 177-182) y sobre la absorción de "El aserradero" por "Él y el otro" (p. 180), problemas que aquí se tratarán más adelante. 
chuelo", la acción se extiende a Buenos Aires (en donde se desarrollarán también "La tijera", "La flecha y la manzana", etc.). Esto no crea, de todos modos, una fractura espacial, pues se trata del espacio del cercano exilio de los paraguayos, y el mundo urbano está descrito con las mismas connotaciones de voracidad e inclemencia que la selva.

Otro parámetro para la constitución de un sistema lo da, a partir de El trueno entre las hojas, la homogeneidad temporal. La extensión cronológica - sea como tiempo del desarrollo de la acción, sea como tiempo del recuerdo- sitúa hechos y personajes en un calendario cuya precisión remite obsesivamente a épocas de desorden histórico. El obispo de "El viejo señor obispo" ha nacido "en los terribles días de la Guerra Grande" (1864-1870); en el trasfondo de "El karuguá" está la Guerra del Chaco (19321935); en otros casos, como en "La excavación", se trata de las guerras civiles, prácticamente ininterrumpidas, y de sus consecuencias. Como el espacio, ésta es una constante de los conjuntos posteriores (salvo la dilatación hacia el pasado de "Niño azoté", en Los pies sobre el agua).

Los datos espacio-temporales parecen determinar la constante temática: la violencia. Un Paraguay sometido a la explotación externa e interna conlleva esta visión de la violencia no como experiencia individual sino como nefasto destino nacional. Todas las historias de El trueno entre las hojas cuentan en última instancia el enfrentamiento de dos fuerzas, por lo general desproporcionadas, en el que el único resultado posible es la derrota del personaje más débil, ya sea por una debilidad física, como los adolescentes de "Regreso", ya sea por una debilidad psicológica, como la cleptomanía que, en "Audiencia privada", sirve de pretexto para el encarcelamiento del protagonista o ya sea porque una determinada situación social impide tomar actitudes extremas, como sucede con el obispo de "El viejo señor obispo". Y si no se puede hablar de derrota en sentido estricto, lo mínimo que se produce es una fractura, una pérdida irreparable, como la que experimenta el niño de "Cigarrillos Máuser', para quien la iniciación sexual queda ligada a la muerte. El dato unificador de la violencia emerge también en los libros siguientes, a veces bajo formas más sutiles y solapadas como el engaño con que la joven de "La tijera" (en El baldío) termina por hacer enloquecer a su tía - respuesta a la violencia que la tía ha ejercido sobre ella, al mantenerla en el encierro y la ignorancia ${ }^{6}$.

${ }^{6}$ Un análisis más detallado debería sobrepasar la violencia como puro 
Estamos, pues, ante un mundo perfectamente compacto en sus parámetros espacio-temporales y en la sustancia de su contenido; una confirmación ulterior de esto podría darla el análisis de los personajes, de su tipificación social o psicológica. Todos estos elementos contribuyen a la definición de un sistema, pero por su extrema generalidad no pueden considerarse como ejes organizadores de los conjuntos particulares: por sí solos no nos permitirían formular una respuesta, o por lo menos una hipótesis, sobre la recodificación de los cuentos dentro de cada conjunto.

Desde esta perspectiva, una articulación de mayor complejidad está dada, en El trueno entre las hojas, por la recurrencia de personajes y situaciones. La lectura de los tres primeros cuentos ("Carpincheros", "El viejo señor obispo", "El ojo de la muerte") procede de manera independiente, colocándolos simplemente en el mismo ámbito espacio-temporal. Al llegar a "Mano Cruel", se explicita una primera relación, casi casual, con el cuento inmediatamente anterior. "El ojo de la muerte" termina con la descripción de una tempestad apocalíptica que se traga al protagonista, Timó Aldama, mientras va acercándose a Villa Encarnación: “...avanzó unos pasos más hasta que el vientre verdoso y mercurial de la tormenta lo chupó hacia adentro para parirlo del otro lado, en la muerte"' (p. 65) ${ }^{7}$.

La tormenta que en "El ojo de la muerte" centraliza la historia, dando cumplimiento a las predicciones de una gitana sobre la muerte de Timó, tiene efectos menos sobrecogedores en "Mano Cruel": aquí arrastra el circo que Mano Cruel ha comprado en Villarrica gracias a las ganancias obtenidas con sus trapisondas, y donde trabaja por una mísera paga su compinche Críspulo Gauto: "El ciclón que destruyó a Villa Encarnación les dejó a ambos la vida, pero se llevó el circo"' (p. 73).

Se trata de una notación brevísima, funcional a la historia de

dato temático y profundizar, en el plano lingüístico, el entrecruzamiento del español y el guaraní: la voz inevitablemente en español del narrador y las voces de los desamparados para las cuales la mímesis del diálogo restituye en algunos momentos la lengua indígena. El vocabulario final, por otra parte, constituye el reconocimiento implícito de que el lector es ajeno a este mundo. Una reflexión sobre este problema se encuentra en A. ROA BASTOS, "Escritura y liberación. (La narrativa paraguaya en el contexto de la narrativa hispanoamericana actual)", en J. M. López de Abiada y J. Peñate Rivero (eds.), Perspectivas de comprersión $y$ de explicación de la narrativa latinoamericana, Casagrande, Bellinzona, 1982; R. BAREIRO SAGUIER, "Estratos de la lengua guaraní en la escritura de Augusto Roa Bastos", en ibid.

${ }^{7}$ En El trueno entre las hojas, Bruguera, Barcelona, 1977. 
Críspulo y Mano Cruel -en el sentido de que la pérdida del circo provocará otras aventuras - pero que, sobre todo, sirve para crear entre los dos cuentos una estrecha relación de contemporaneidad. A otro nivel, la indicación menos funcional "les dejó a ambos la vida" unifica los destinos de Timó Aldama (con quien el ciclón fue menos clemente), de Mano Cruel y de Críspulo Gauto: todos son ejemplares intercambiables de una desgraciada humanidad. barrida por vientos literales y metafóricos.

$\mathrm{El}$ salto se hace más grande de "El karuguá" a "Mano Cruel": ahora la memoria del lector debe remontar cinco cuentos, y colocar en relación de contemporaneidad la historia de Mano Cruel y la del mesías Aparicio Ojeda. En "Mano Cruel", Críspulo recuerda una de las "gracias" de su socio: "...había puesto un nido de kavichu'í bajo la silla de un demente que se hacía pasar por enviado de Dios y tenía enloquecida a la pobre gente con sus sermones lunáticos'” (p. 72).

Este hecho, meramente ilustrativo en "Mano Cruel", se vuelve determinante en "El karuguá". La broma de las avispas hace perder al "enviado de Dios" Aparicio Ojeda su ascendiente sobre la gente del pueblo, que a partir de ese momento lo abandona. La relación no es pues sólo de contemporaneidad, sino que se revela fundamentalmente como enlace causal:

Un muchachón zafado, un calesitero llamado Mano Cruel, que estaba de paso por este pueblo, le puso bajo la silla, nunca te supimo cómo pa pudite, un nido de kavichu'í [...]. El resucitado escapó saltando como un mono, pidiendo socorro a grito pelado, arrugado, deformado por la picazón de la' avipita y por el enojo [...]. Desde entonces nadie lo quiso creer. Diparábamos o no' reíamos de él diretamente. Terminó acorralado en su i'la. Poco depué se jué a vivir al karuguá de Yvirá-Kaigüé (p. 144).

Un cuento se refleja en el otro, en un caso anticipación, en el otro reminiscencia, pero ambas sutilmente asimétricas. Lo mismo sucede entre "El ojo de la muerte" y "La rogativa" (que ocupa el décimo tercer lugar). Lo que en el primero es un simple dato informativo, de caracter cronológico ("Todavía no se había 'juntado' con Anuncia, todavía Poilú no había nacido', p. 60), en el segundo se vuelve núcleo de la historia: la miseria y la degradación de la mujer y la hijita de Timó Aldama después de la muerte de éste, es decir, como una consecuencia implícita de esa muerte.

En este punto, se hace evidente el juego de la síntesis memorial, que confiere a datos marginales el carácter de anticipaciones. A través de una serie de bruscos regresos, que permiten al 
lector colocar personajes y situaciones en un esquema cada vez más complejo, los cuentos se proponen como fragmentos de una totalidad. El trueno entre las hojas no se constituye, pues, como una progresión de informaciones, sino como una reconstrucción parcial que, si bien no completa todos los claros, indica la posibilidad de completarlos y que, por otra parte, hace cumplir al lector un recorrido cada vez más amplio. Así es como, coherentemente, el último de los cuentos ("El trueno entre las hojas") remite al primero ("Carpincheros'), dándole una prosecución temporal y lógica.

"Carpincheros" es, sobre todo, la historia de una partida. Al ingenio de Tebikuary del Cuayrá ha llegado una pareja de inmigrantes alemanes con su hija. La pequeña Gretchen, atraída por la imagen de libertad y de fusión con la naturaleza que irradian los carpincheros, en contraste con el régimen de semiesclavitud en que viven los trabajadores del ingenio, huye de su casa y abandona a sus padres para seguir a los hombres libres del río.

"El trueno entre las hojas", que cuenta la pasión de justicia y la pasión de amor de Solano Rojas, se coloca cronológicamente antes y después de "Carpincheros", al que abarca y da su sentido final. La historia de Solano Rojas forma parte de los antecedentes de "Carpincheros"': a los quince años trabaja en el ingenio cuyo dueño es el inescrupuloso Simón Bonavi (citado en el primer cuento); tiene aproximadamente diecinueve cuando es asesinado Eulogio Penayo, el cruel testaferro de Bonavi (cuyo fantasma, en "Carpincheros", sigue rondando el lugar del crimen). A su vez, "El trueno entre las hojas" resume en pocas líneas la trama de "Carpincheros", reduciéndola a una anécdota más o menos legendaria:

Se decía que el alma en pena de Eulogio Penayo se lamentaba allí por las noches. Después la ocupó otro matrimonio alemán que tenía una hijita de pocos años.

Una noche que trajeron a la casa un carpinchero muerto por un lobo-pe, la niña desapareció misteriosamente [...]. La madre enloqueció al ver que el cadáver del carpinchero se transformaba en un mulato, un mulato gigantesco que lloraba y se reía [...]. Afirmaba que él había robado a su hijita (p. 233).

La relación entre ambos cuentos, sin embargo, no es sólo la de explicitación recíproca de antecedentes: en "El trueno entre las hojas" terminan por encontrarse, años más tarde, los destinos de Gretchen y Solano Rojas. Simón Bonavi vende su ingenio porque los trabajadores, encabezados por Solano, empiezan a rebe- 
larse. Bajo la férula del nuevo propietario, Harry Way, la violencia y el terror aumentan. Los carpincheros salvan a Solano, brutalmente torturado por los capangas de Harry Way, y combaten a su lado cuando finalmente estalla la rebelión en el ingenio. En la figura femenina que los acompaña no se puede dejar de reconocer a la Gretchen de "Carpincheros", transformada ahora en una adolescente:

Entre los carpincheros, cerca de Solano Rojas, estaba una muchacha mirando la casa que ardía. En su rostro fino y pequeño sus pupilas azules brillaban empañadas. La firme gracia de su cuerpo de cobre emergía a través de los guiñapos. Sus cabellos parecían bañados de luna como el azúcar. No tenía armas pero sus manos estaban cubiertas de tizne. Ella también había ayudado a quemar la Ogaguasú, a destruir la cruel y sanguinaria opresión que estaba acabando en calcinados escombros, en humo volandero, en recuerdo (p. 247).

"El trueno entre las hojas" cierra así un ciclo no sólo por lo temático, no sólo por la recurrencia de personajes y espacios, no sólo porque explica el primer cuento. Lo cierra porque da al conjunto entero la misma forma que tiene cada cuento tomado aisladamente y a la que sólo el primer cuento - tomado aisladamenteescapa: la forma de un regreso.

En efecto, el regreso es la forma que organiza el contenido de cada cuento y del conjunto, el eje que nos permite leerlos como una totalidad, y que en el último de los cuentos rescata al conjunto del signo negativo que lo dominaba. Regresa el señor obispo a su tierra, en donde encontrará la desilusión y la muerte; regresa Timó Aldama a poner fin a una partida de truco y cumplir una profecía fatal. Críspulo Gauto vuelve a encontrar a Mano Cruel transformado en un poderoso personaje, que para evitar fastidiosos reconocimientos lo manda a la cárcel. "Galopa en dos tiempos" vuelve a enfrentar, irreconocibles por el tiempo y el desengaño, a los protagonistas de una historia sentimental. $Y$ "Regreso" lleva por título el cuento en el que un jovencito, que se fue de su casa para probar su hombría, al volver encuentra sólo la destrucción: la casa ha sido confiscada, su hermano cae ante el pelotón de fusilamiento.

En algunos casos el regreso puede aparecer como un desplazamiento mínimo, pero resulta siempre determinante: en "Pirulí", una mujer que se ha alejado de la casa dejando al hijo a cargo del trapiche, lo encuentra al retorno con el brazo triturado por la maquinaria. Al descubrir que sólo había sido una broma para 
asustarla, exasperada, lo golpea de tal modo que le causa la muerte. En otros casos, el regreso tiene un carácter metafórico: el prisionero político de "La excavación", mientras va cavando un túnel que debería llevarlo a la libertad, y que en cambio se derrumbará causando su muerte, regresa con la memoria a otro túnel: el que años atrás, durante la Guerra del Chaco, había cavado junto con sus compañeros para atacar a las tropas bolivianas.

Todos los cuentos de El trueno entre las hojas se inscriben en este esquema, de manera más o menos explícita. Todos, salvo "Carpincheros". Esta excepción es significativa por el modo en que, como hemos visto, se resuelve en el texto final: en "El trueno entre las hojas" Gretchen regresa, años más tarde, para ayudar a los trabajadores del ingenio en el momento de la rebelión y de la lucha. Allí es donde nace el amor de Solano Rojas hacia la muchacha desconocida, a la que llamará con un nombre guaraní, Yasy-Mörötí.

Ese amor no llega a realizarse, pues Solano Rojas es apresado y debe pagar su rebelión con quince años de cárcel. Regresa ciego al lugar en donde se yerguen las ruinas del ingenio, y con sus palabras sigue difundiendo la idea de libertad y de justicia. Cuando muere ahogado en el río, regresan los carpincheros a llevárselo definitivamente. Y otra vez con ellos está la mujer de ojos azules y rostro cobrizo: "Sobre la balsa, al lado del muerto, iba inmóvil Yasy-Mörötî”' (p. 250).

Ahora bien, a diferencia de las demás ocasiones, en las que el nombre era pronunciado por Solano, o de todos modos referido a su palabra, este "Yasy-Mörötî"' se coloca en otro plano. Al ser atribuido a la voz del narrador, no aparece como derivado de una invención de Solano, sino que designa el ser del personaje: esa mujer es Yasy-Mörötí. La hija de inmigrantes alemanes ya no existe. En su lugar hay ahora una mujer que pertenece a la tierra en que vive; pero que, a diferencia de los trabajadores del ingenio, del mismo Soląno Rojas, no ha pagado esa pertenencia con la esclavitud. Lo sugiere también el espacio en que se desplaza, el río. Con sus características de fluidez, de eterno movimiento, remite simbólicamente a la idea de libertad; así como encarnan imágenes de libertad los carpincheros, con quienes YasyMörötí ha elegido compartir su destino.

El conjunto de los cuentos se eleva de este modo a una dimensión que va más allá de la que propone cada cuento tomado sepa-

- radamente, y abre para esas historias de abyección, de muerte y de derrota, la posibilidad de un cambio, al enmarcarlas entre dos signos positivos: la elección del propio destino y la reafirmación de la libertad. 
El baldio reúne once cuentos que, respecto a los del conjunto anterior, se presentan como entidades independientes. Sin embargo, un dato estructural se repite: como en El trueno entre las hojas, la recurrencia de personajes o de hechos establece entre los textos una serie de relaciones internas. Estas relaciones no son siempre homogéneas sino que, para algunos cuentos, indican diferentes grados de realidad textual. Es decir, en algunos casos la relación es de tipo consecutivo o causal, como en El trueno entre las hojas, mientras que en otros se produce una asunción total o parcial de un cuento dentro de otro, del que pasa a formar parte, pero en un nivel narrativo distinto ${ }^{8}$.

"Encuentro con el traidor", "La tijera" y "La flecha y la manzana" - que, aun continuando el mundo paraguayo, se desarrollan en Buenos Aires- están unificados por el tipo de relaciones que existen entre los personajes. En "La flecha y la manzana", un señor de visita espera al dueño de casa y, mientras tanto, conversa con la mujer y los hijos de éste. Los datos que emergen de la conversación (el hombre tiene un ojo de vidrio, tanto él como el dueño de casa son paraguayos, han vuelto a encontrarse después de treinta años) permiten que el lector identifique al visitante como uno de los personajes de "Encuentro con el traidor": el presunto traidor, a quien la vidà vuelve a poner frente a una de sus víctimas - el dueño de casa. "La flecha y la manzana" especifica además el apellido de este último, con lo que el lector puede identificarlo como el padre de los niños que la joven protagonista de "La tijera" va a cuidar casi todos los días, y en cuya casa conoce al exilado paraguayo que será su amante.

En "La flecha y la manzana", que tanto cronológicamente como por su colocación en el conjunto se sitúa después de los otros dos, se esclarecen elementos que resultaban marginales en "Encuentro con el traidor"' y "La tijera", con los que se sitúa en un mismo nivel narrativo. La relación que se establece entre "Él y el otro" y "El aserradero" no puede, en cambio, definirse como continuidad ni como contigüidad. Se trata de un fenómeno completamente distinto, por el cual uno de los cuentos canibaliza al otro. "Él y el otro" absorbe la totalidad de "El aserradero", transformándolo en materia de la narración del personaje narrante, definido por otra voz como "el gordo", y cuya única realidad, al menos en este cuento, es la de narrar tres historias entrecruzadas: la de los enanos de un circo (que volveremos a encontrar en

${ }^{8}$ Sobre el problema de los niveles narrativos, remito a G. GENETTE, Figures III, Éds. du Seuil, Paris, 1972, quien ha propuesto útiles distinciones. 
Moriencia), la de un robo en un tren (del que el narrador ha sido testigo) y la de "El aserradero", resumida y, sobre todo, interpretada.

Esta absorción no significa simplemente la cita de un cuento dentro de otro, es decir un caso de intertextualidad en sentido amplio ${ }^{9}$ O bien, definiéndolo en estos términos, lo importante es el modo y el sentido con que esta relación intertextual se establece. Si he hablado de canibalismo de "Él y el otro" respecto a "El aserradero", es porque el cuento mismo sugiere la imagen. En efecto, para explicar la completa desaparición de uno de los personajes, el narrador propone su interpretación de los hechos:

. . aquí no podemos más que barajar conjeturas quién puede andar seguro en el tembladeral de las cosas humanas y no adelantamos nada si entramos a sospechar que ese hombre quemado hasta el fondo por su obsesión no se contentó solamente con asesinar al amigo arrojándolo al agujero insondable del cerro o más creo yo haciéndolo desaparecer en el pozo sin fondo de su propia obsesión devorándolo como quien dice en un acto de antropofagia ritual ( $p$. $125)^{10}$.

Esta hipótesis de antropofagia literal entre los personajes puede ser extendida metafóricamente al tipo de relación entre los textos. "Él y el otro" integra en sí a "El aserradero", lo vuelve materia de su propio ser. Lo que en "El aserradero" aparecía como "realidad objetiva" - gracias a la convención por la cual una voz narrante neutra concede estatuto de realidad a lo narrado-, en "Él y el otro" se vuelve puro acto verbal, realidad mediatizada por una palabra que no se propone como transparencia sino, explícitamente, como literatura: como reinvención de la realidad. Más precisamente, como sustitución de la realidad.

Este tipo de relación duplica, en otro plano, el eje según el cual se organiza cada uno de los cuentos del conjunto: una sustitución. "Encuentro con el traidor", por ejemplo, narra el encuentro inesperado de dos hombres. Existe entre ellos una enconada enemistad que dura desde hace treinta años: desde que uno de los dos provocara, delatando al otro y a todos sus compañeros, el fracaso de una insurrección. Pero en realidad el odio es inmerecido, pues "el traidor" no es tal, sino que ha asumido una culpa ajena:

${ }^{9}$ Sobre los distintos uso del término "intertextualidad", las indicaciones más completas están en G. GenetTe, Palimpsestes, Éds. du Seuil, Paris, 1982.

${ }^{10}$ En El baldio, Losada, Buenos Aires, 1966. 
Cómo iba a explicarle ahora, después de treinta años, que yo no fui el delator, sino mi hermana. Él murió en el Chaco como un héroe. Yo seguí viviendo como un infame. La diferencia no es grande cuando hay de por medio un secreto como el mío. Y cómo explicarle que mi papel me gusta, que al fin ha llegado a gustarme de veras (p. 28).

Se trata, pues, de la asunción de un rol, en este caso voluntaria, aunque las motivaciones no sean explícitas; de un rol que termina por volverse identidad, ya que es el único reconocido por los demás. Esta sustitución de funciones, por otra parte, no es un hecho individual. El cuento mismo sugiere su colocación en un esquema generalizado, cuya causa ha de buscarse en el caos político imperante, que hace intercambiables los destinos:

Y otra vez revoluciones, conspiraciones y sublevaciones como la nuestra, con nuevos héroes y traidores, en una cadena interminable. Los verdugos de la víspera convertidos en víctimas, las víctimas convertidas en verdugos al día siguiente (p. 26).

Si nos colocamos en esta perspectiva, podemos leer la historia de "El baldío" como la de un hombre que, de presunto asesino (se lo entrevé arrastrando un cadáver en un basural), se transforma en salvador (descubre entre las basuras a un recién nacido, lo arropa con ternura y se lo lleva consigo); en "La tijera" una adolescente finge ante sus tías mojigatas ser la asesina de un depravado, de quien además estaría esperando un hijo, cuando en realidad se ha enterado de este crimen por los diarios. En "El aserradero", Eulogio Esquivel, desde siempre enamorado de la mujer de su amigo, atrae a éste a una celada, lo mata, y antes de huir toma su lugar en la cama de la mujer, sin que ésta advierta la sustitución.

En otros casos, como en "El pájaro mosca", la sustitución no es voluntaria. Alba, una joven que sufre la alucinación de criar un pájaro mosca invisible, es violada por los soldados de la guardia presidencial. Al encontrarla moribunda, su amiga Delmira pierde la razón y asume la locura de Alba: ahora es ella quien alimenta y arrulla al inexistente pájaro mosca. Ahora bien, esta sustitución, que cierra el cuento, se inserta en otra, que constituye su línea fundamental: el padre de Alba, por descuido o intencionalmente, sustituye un antiguo ejemplar del Quijote - que su pobreza le obliga a vender a su enemigo, el padre de Delmira- 
con una autobiografía en la que se aclaran las razones del odio que separa a los dos hombres ${ }^{11}$.

En "Borrador de un informe", el planteo se hace más complejo: en este cuento se descubre que dos ladrones enmascarados que van a robar las ofrendas de los fieles, y que el párroco mata de un balazo, son en realidad el alcalde y el juez; un mercachifle sustituye su víbora amaestrada con una yarará venenosa; la yarará será utilizada por quien redacta el informe para asesinar a una prostituta, que en la procesión aparece como una penitente; toca al asesino, en su papel de investigador, establecer las causas de la muerte en el informe, transformando el asesinato en accidente. Otras sustituciones pueden ser más sutiles, como en "La flecha y la manzana" (la modosa niñita agredida por los hermanos es en realidad una feroz agresora) o en "Hermanos" (un hombre debe decidir entre su papel de hermano o de soldado); mientras que en "La rebelión" el acento está puesto sobre el movimiento inverso: quien escribe el testimonio que constituye el cuento lo hace para restituir una verdad negada.

El eje de la sustitución en su doble aspecto - el de dos identidades o roles y el de la realidad literaria o no de un hecho- encuentra una sanción general en "Contar un cuento". Aquí el protagonista, "el gordo", descrito como un narrador de habilidad fuera de lo común, cuenta la historia de un hombre que había soñado el lugar en donde moriría, pero no lograba identificarlo. Cuando por fin lo consigue, se da cuenta de que se trata de su propio cuarto. Llegada a este punto de la narración, la voz del narrador se quiebra en el estertor de la muerte, y los oyentes reconocen en el cuarto tan minuciosamente descrito el lugar en donde se encuentran.

Estamos pues ante el caso inverso de "Él y el otro" (atribuido) por lo demás, como veremos luego más detalladamente, al mismo narrador), del que "Contar un cuento" aparece como imagen especular. En aquél un hecho "real" era absorbido como materia literaria; en éste, la materia literaria se vuelve paradójicamente "realidad". Estos dos cuentos, que ocupan el segundo y el penúltimo lugar, encerrando a todos los demás -excepto "El baldío" y "El pájaro mosca" - en su juego de implicación y sustitución, definen el entrecruzamiento entre los dos planos, el "real" y el "literario", como inevitable: la literatura como sustitución de la

11 Para H. RODRíguez AlCALÁ, en cambio, este cuento carece de una estructuración unitaria, mereciéndole el juicio de "experimento fallido" ("Dos cuentos de Augusto Roa Bastos", en Narrativa hispanoamericana, Gredos, Madrid, 1973. 
vida, pero también la vida como sustitución de la literatura.

No sería entonces arriesgado sugerir, a partir de uno de los cuentos, la posibilidad de llevar el entrecruzamiento a un plano aún más complejo: del libro a la realidad extratextual. Una alusión de "La tijera" deja entrever, en efecto, una proyección fantástica del autor en su propio texto: ese exilado paraguayo que planea escribir "una novela, y varios cuentos" (p. 95) tal vez los mismos que estamos leyendo.

Con Los pies sobre el agua se inaugura otro tipo de composición, pues sólo hay tres cuentos totalmente nuevos: "Nonato", "Ajuste de cuentas" y "Niño-azoté". "Macario" y "Hogar" son en realidad dos capítulos de Hijo de hombre (respectivamente el primero y el quinto). Los restantes provienen de El trueno entre las hojas ("La excavación", “El karuguá", "La gran solución”) y de El baldio ("Borrador de un informe", "La rebelión"). Creo que, en líneas generales, se puede hablar, para estos cuentos retomados, de un desplazamiento del eje de lectura, generado por el primero de los cuentos de este conjunto, "Nonato", que traza la línea de la construcción de una memoria. No se trata de borrar los esquemas del regreso o de la sustitución, destacados en los conjuntos precedentes, ya que estos mismos esquemas se incluyen en el eje de la memoria: regreso al pasado, sustitución de lo vivido por lo recordado (por otra parte, Los pies sobre el agua carece de "memoria interna", es decir, de citas de un cuento dentro de otro, perteneciente al mismo conjunto; aquí el proceso de reconstrucción, por parte del lector, supone el conocimiento de los libros anteriores).

"Nonato" puede ser definido como una memoria que se busca, precisamente porque se le niega la posibilidad de ser memoria:

Cuando usted me dice que yo no puedo acordarme tan lejos, que nadie en su sano juicio puede hacerlo, y que yo ya estoy crecido para andar perdiendo el tiempo en chocheras de chico, yo me callo. Sólo por fuera. Sin nadie a quien hablar de estas cosas, ya que usted tampoco quiere escucharme, me quedo hablando conmigo mismo, para adentro (p. 5) ${ }^{12}$.

Se trata, en este caso, del obsesivo recuerdo del padre, y del imposible amor del narrador por la madre, a quien inútilmente trata de comunicar esos "Recuerdos de antes de nacer" (p. 6). La memoria, aunque los demás la nieguen, es una verdad indiscutible. Algo que se alimenta de sí mismo y se reproduce: "Pujo por

${ }^{12}$ En Los pies sobre el agua, C.E.A.L., Buenos Aires, 1967. 
acercarle esos recuerdos para que usted también los vea como los veo yo, parecidos a grandes pájaros cluecos empollando los otros recuerdos más chicos de después" (p. 6).

La función de los recuerdos, de todos modos, es generar desamparo. La materia del recuerdo es, aquí como en los demás cuentos, negativa, dolorosa, cargada de muerte (en "Nonato" los soldados que buscan al padre para matarlo y violan a la madre, en "Hogar" una fuga a través del monte, en "Ajuste de cuentas" el degüello de un general torturador). Los recuerdos del narrador coinciden con los de la madre, pero ella les niega autenticidad, dado que sólo se puede rememorar la propia experiencia: "Déjese de porfiar en lo que no conoce. Me ha oído hablar a mí de esas cosas, y de ahí saca que las ha visto pasar. Nadie puede acordarse sino de lo que le ha sucedido a uno mismo"' (p. 11).

Esta frase puede leerse como clave de los cuentos siguientes: lo que cada cuento narra, en realidad, es el intento de reconstruir el pasado del otro. Las motivaciones de esta búsqueda van de la curiosidad ("El karuguá") a la necesidad interior ("Hogar"), a la transformación legendaria de un hecho histórico revivido mediante un ritual ("Niño-azoté").

"Macario" es el cuento en el que con mayor claridad se evidencia este entrecruzamiento de memorias. Macario mismo es un narrador de segundo grado, introducido por un primer narrador para quien Macario es ya un recuerdo, "una aparición del pasado" (p. 14). La memoria de Macario, que ha tamizado los hechos, será a su vez tamizada por la memoria del narrador:

Yo era muy chico entonces. Mi testimonio no sirve más que a medias. Ahora mismo, mientras escribo estos recuerdos, siento que a la inocencia, a los asombros de mi infancia, se mezclan mis traiciones y olvidos de hombre, las repetidas muertes de mi vida. No estoy reviviendo estos recuerdos; tal vez los estoy expiando (p. 18).

Ahora bien, si la madre de Nonato negaba la existencia de recuerdos ajenos, Macario ofrece la demostración viviente de lo contrario: puede existir, existe una memoria colectiva que se externa en un individuo. Él recuerda hechos y personas que pertenecen a la historia de su país, y que por una circunstancia particular - ser hijo del liberto Pilar, ayuda de cámara del doctor Francia - ha conocido de muy cerca. Así Francia, Bonpland, la Guerra Grande, se animan a través de la palabra de Macario, se vuelven cosa viva, percibida en primera persona por todos los que lo escuchan: "La veíamos cabalgar [a la sombra de Francia] 
en su paseo vespertino por las calles desiertas, entre dos piquetes armados de sables y carabinas" (p.19).

Del mismo modo, en la palabra de Macario revive una historia más cercana que los demás ignoran, o no quieren recordar: la historia de Gaspar Mora, sobrino de Macario y constructor de instrumentos musicales que, leproso, se aisló en la selva y al morir dejó al pueblo un hijo de sus manos, una estatua de Cristo tallada en madera.

"Ajuste de cuentas" se publica por primera vez en este conjunto, pero su prefiguración está en un cuento de El baldío, cuyo narrador se refiere a "unos emigrados que consiguen asesinar al embajador de su país con la ayuda de un ciego. El gordo sostenía que el ciego había apuñalado al militarote, sentenciado desde hacía mucho tiempo por sus actos de sevicia y por haber organizado y dirigido el aparato de represión del régimen. El atentado y el crimen eran absurdos e increíbles, según el relato del gordo" ("Contar un cuento", en El baldío, p. 17). Ése es el resumen de la historia que en "Ajuste de cuentas" aparece como la rememoración de uno de los personajes implicados en el crimen. Tal vez se trate del asesino mismo, pues aunque una versión diga que el autor del crimen ha sido el ciego, éste ha negado siempre su participación, y por otra parte, en la habitación del narrador se destaca un macabro trofeo: el frasco con las orejas de sus víctimas, que el militar apuñalado conservaba en alcohol. La línea de una ambigua y probable sustitución de identidad se superpone aquí a la reconstrucción de la memoria.

El narrador de "Hogar", en cambio, tiene conciencia de no poseer una memoria propia de los hechos: "Yo sabía la historia; bueno, la parte pelada y pobre que puede saberse de una historia que no se ha vivido"' (p. 119).

Es por eso que la busca en otro personaje, Cristóbal Jara, quien lo guía por un camino perdido en la selva - doble metafórico del recorrido hacia atrás de la memoria - hasta el lugar perdido en el monte donde está el vagón en el que se refugiaron Casiano Jara y su mujer después que el tren de los rebeldes fue destruido por las bombas. Al penetrar en esa memoria, concretizada en el vagón, el narrador se vuelve partícipe de ella, la asume en su presente. Así, cuando un grupo de hombres surge del monte para pedirle que los guíe en la inminente revolución, baja de la plataforma - ¿del pasado? - y dice "Vamos".

"Niño-azoté", desde el punto de vista de la construcción, no es absolutamente homogéneo en relación con los cuentos ya citados; lo es, en cambio, si se piensa que, contado como presente 
por un narrador externo, no propone el hecho en sí - que pertenece al pasado, al "ardiente y último día de diciembre de 1743" (p. 133) - sino su actualización mediante un ritual. Una madre, enloquecida por la muerte de su hijo, roba la imagen del niño Jesús del pesebre de las celebraciones navideñas. El malón que la rapta después de haber destruido el pueblo cree que se trata de un niño real, y efectivamente el milagro se produce: cada vez que los indios se le acercan, la estatua se anima y ella la amamanta, salvándose así de seguras vejaciones. El pasado se restaura aquí no a través de una reminiscencia individual, sino en una representación colectiva que, por su carácter ritual, lo transforma en un presente cíclicamente renovado, ilustrando la verdad de una afirmación aparentemente insensata de "Nonato": "Lo que para usted ha sucedido una vez, para mí vuelve a suceder una y otra vez, de la misma manera, sin descanso"' (p. 7).

Según este eje de la memoria actualizada puede releerse " $\mathrm{La}$ excavación": la memoria del prisionero constituye el espacio de su fuga. El túnel excavado durante la Guerra del Chaco forma "un único agujero recto y negro" (p. 158) con el que está cavando bajo la prisión. ¿En cuál de los dos muere? ¿En el presente, por un derrumbe, o en el pasado, abatido por la ametralladora de un soldado enemigo?13. Del mismo modo, "El karuguá"' se presenta como búsqueda de una versión fidedigna, por parte del narrador, de la historia de los habitantes de la ciénaga. ¿Isabel Miscowsky, la joven que vive segregada por Sergio Miscowsky, es hija de la unión incestuosa entre éste y su hermana, como sugiere la posadera del pueblo, o de la hermana y el mesías Aparicio Ojeda, como cuenta el mismo Sergio, que fue uno de los secuaces de Ojeda? El narrador, a pesar de sus estratagemas, no conseguirá ver a la muchacha, y la verdad seguirá suspendida entre esas verdades divergentes. En este conjunto, se acentúa el testimonio falaz de la memoria de "Borrador de un informe": memoria que queda escrita para ocultar premeditadamente la verdad.

"La gran solución" y "La rebelión" se ven unidos sólo lateralmente a esta línea de lectura: el primero, porque se propone como la progresión de una aventura; el segundo, porque su estructura verbal sugiere una experiencia presente, aunque el final revele su carácter de testimonio escrito en el pasado: "Por eso escribo esto, para que se sepa lo que ocurrió'” (p. 109).

13 Respecto a la versión publicada en El trueno entre las hojas, el cuento presenta aquí variantes (procedimientos de reducción y de amplificación) que podrían analizarse desde esta perspectiva. 
El eje de la memoria, aunque preponderante, no ha absorbido completamente los materiales, que parecen buscar aún una colocación definitiva: la que encontrarán en Moriencia.

Antes de abordar Moriencia debemos detenernos en Madera quemada, selección de cuentos preparada por la editorial, cuya mayor preocupación ha sido la de no repetir los cuentos incluidos en Los pies sobre el agua, publicado casi contemporáneamente ${ }^{14}$. Son inéditos, en este conjunto, "Bajo el puente" y "Kurupí", aunque este último ha sido concebido como un capítulo de la novela $H$ ijo de hombre, en la que, completamente modificado, da origen a distintos episodios.

En Madera quemada, como en Los pies sobre el agua, no se manifiesta un encadenamiento entre los textos, creado por algún tipo de recurrencias, y resultaría forzada la identificación de un eje de lectura que fuera más allá de la unificación temática, la violencia.

Se puede rastrear de todos modos una línea común, que tendería a dar al conjunto cierta unidad más o menos aleatoria: la presencia de un conflicto espacial. En estos cuentos los personajes se ven proyectados en espacios ajenos, produciendo un efecto de invasión o de pérdida, según el enfoque que se elija. En "'Kurupí", Melitón Isasi actúa como dueño de un pueblo del que no forma parte, y sus habitantes lo consideran como un ser maléfico llegado de una dimensión sobrenatural; en "Niño-azoté" el malón invade el espacio urbanizado por los blancos, llevándose a una mujer; "El trueno entre las hojas", narra la expoliación del espacio que sufren los pobladores de Tebikuary del Guayrá por obra de Simón Bonavi y Harry Way, provenientes de un espacio exterior, mientras que de otro espacio, el río, vienen los carpincheros salvadores; etc.

Este conflicto expresado en términos espaciales aparece más bien derivado del plano temático global de la obra de Roa Bastos: la explotación y la injusticia creadas por el momento histórico, que llegan a provocar la percepción del espacio propio, como ajeno. Suficientemente explicíta al respecto es la reflexión propuesta por "Bajo el puente", en el momento en que un niño iza la ban-

${ }^{14}$ Aclara en efecto la "Nota preliminar" de PEDRO LASTRA: "La selección de cuentos que hemos preparado muestra la amplitud de percepción de la realidad y la expresión adecuada que ella encuentra en los planteos narrativos de Roa Bastos. Hemos tratado de no repetir las piezas incluidas en el volumen editado en junio de 1967 por el Centro Editor de América Latina, de Buenos Aires, con el título de Los pies sobre el agua..." (en Madera Quemada, Editorial Universitaria, Santiago de Chile, 1967, pp. 10-11). 
der de la escuela: "Con todo el sol y las moscas juntas, el cielo y la tierra dan vueltas alrededor del asta. Una bandera. ¿De qué patria sería?"' (p. 50).

La lectura de Madera quemada reconstruye, más que un eje definitorio de un sistema textual, una cosmovisión - obviamente unitaria, pero carente de una especificidad organizadora. El ejemplo más evidente de reducción de sentido lo ofrece el cuento que cierra el conjunto, "El trueno entre las hojas". Mientras en el conjunto que lleva el mismo nombre su colocación final cumple una función, pues remite al comienzo, indica un regreso, concluye una parábola, aquí se encierra en sí mismo, sin que pueda aflorar, entre otras cosas, el concepto de elección del propio destino.

Moriencia presenta el caso opuesto: la reproposición de cuentos publicados anteriormente, según una línea que les confiere nueva significación y los hace más compactos. En Moriencia el eje de la memoria actúa como organizador de todo el conjunto: por una parte, los cuentos remiten unos a otros, en una especie de memoria interna; por otra, la memoria $-y$, sobre todo, su ambigüedad- se presenta como línea constructiva de cada cuento en particular.

El libro está dividido en tres partes: MORIENCIA, JUEGOS NOCTURNOS y BORRADOR DE UN INFORME que, con variantes, se ven unificadas por el problema de la verdad de la memoria, de su relación con una presunta realidad. La primera, encabezada por el cuento "Moriencia" se abre bajo el signo de una contradictoria visión del pasado. Lo que se pone en duda no es la existencia de ese pasado, sino el derecho de la memoria a proponerlo como verdad. El narrador pregunta a una mujer si conoció a Chepé Bolívar (que, por lo demás, es un personaje de Hijo de hombre):

- ¿Al telegrafista de Manorá? ¡Eá, cómo no, si hasta su ropa yo le hacía!

Miente la vieja palabrera, dije entre mí, acordándome de que el telegrafista anduvo casi siempre en cueros (p. 11).

El narrador contradice mentalmente cada afirmación de la mujer, creando en el lector una duda sobre los hechos: ¿era Chepé Bolívar una especie de vagabundo, o estaba siempre encerrado en su rancho? ¿Murió de bala, de susto, o porque tenía que morir nomás? Y sobre todo, ¿cuándo murió?

Son los interrogantes que, con mayor intensidad, plantea el 
último de los cuentos de esta parte, "Cuerpo presente", en el que asistimos al velorio de Chepé Bolívar: "...todo él sigue estando allí, pero ya no es él sino su recuerdo"' (p. 43).

La rememoración se juega aquí sobre dos planos: el intento de reconstruir la "verdadera" muerte del telegrafista Chepé Bolívar, tanto para los que lo conocieron como para los desconocidos que asisten al velorio (el dueño de un circo de paso por el pueblo, el payaso, la mujer barbuda), y el intento del narrador de reconstruir su propia vida. Éstos son los recuerdos que cobran mayor relieve: un aguacero que inunda el pueblo, el salvamento de la perra de María Dominga Otazú, el beso con que ésta agradece al niño...

El maestro del pueblo, personaje lateral de "Moriencia" y de "Cuerpo presente", amigo de Chepé Bolívar, constituye el objeto de la rememoración del narrador de "Bajo el puente". El narrador trata de reconstruir su recuerdo infantil del maestro, y aunque aquí no existe un interlocutor contradictorio como en "Moriencia", la ambigüedad se manifiesta igualmente: vagos son los recuerdos, así como es vaga la percepción de la realidad:

Una noche, del montón [de perros] que se deshacía lo han visto salir completamente desnudo. Embarrado con la baba de los perros se ha metido en su casa. De nuevo tranquilo y seguro. Algunos han dicho que lo han visto entrar en cuatro patas, como los mismos perros. Nunca se ponen de acuerdo en las cosas del maestro (p. 33).

El incierto trazado del retrato del maestro se concluye con el recuerdo de su muerte, que es la única certidumbre del narrador adulto:

Tengo la misma edad del maestro cuando se desgració bajo el puente, esa mañana en que todos los alumnos fuimos en fila a ver su cara bajo el agua barrosa. De golpe había volado hacia atrás, hacia el principio (p. 36).

Ese vuelo "hacia el principio", por una parte legible como metáfora de las operaciones de la memoria, tiene también un significado más literal. Cuando los niños encuentran al maestro muerto, éste parece haber remontado concretamente el tiempo: su cara es "la cara arrugada de un chico. Menos que eso: la de un recién nacido" (p. 36). Ésta y otras notaciones, como vere- 
mos luego, explican la colocación en esta parte de "Nonato", atribuido a otro narrador.

A la misma voz corresponde, en cambio, la rememoración de la infancia en "Ración del león", en la que el narrador recuerda cuando le quitan su perro, confundiéndolo con uno de los animales muertos que los niños llevan al circo para comida de las fiestas, a cambio de una entrada para el espectáculo. A la reflexión sobre esta pérdida se superpone el recuerdo de un juego, una de esas retahilas en las que cada término es corregido por el siguiente (el sol es más fuerte que la helada, porque la derrite, pero la nube es más fuerte que el sol, porque lo tapa, pero el viento es más fuerte que la nube, porque...). La frase con la que el narrador cierra la retahila resume, en cierto modo, el sentido global de estos cuentos:

Si usted se olvida de uno solo de los que están abajo la cadena se rompe, y hay que volver a empezar. Qué pasaría si se pudiera hacer retroceder al tiempo [...]. Tal vez se podría llegar al principio; tal vez hasta lo que está antes del principio (p. 41).

La búsqueda de estos cinco primeros cuentos apunta hacia el trasfondo de la memoria que indaga sobre la vida y la muerte, rastreando sus motivaciones secretas, o por lo menos huidizas.

La segunda parte, JUEGOS NOCTURNOS, plantea en cambio la legitimidad de la transmisión a los demás de la experiencia propia o ajena, es decir, plantea la legitimidad de la narración misma. En el primer cuento, "Juegos nocturnos", el dueño de casa narra a sus invitados un encuentro nocturno de enamorados, que suele tener lugar en su jardín. Pero cuando se oculta con sus huéspedes para asistir, sin ser vistos, a la presunta escena de amor, lo que se oye es "un runruneo de bocas que no se aman sino que discuten" (p. 62), seguido de palabrotas, golpes y sollozos. Esta divergencia proyecta su sombra sobre las otras rememoraciones del narrador: su relación con la inglesa Carolina, que a su vez recordaba obsesivamente la muerte de su marido en un bombardeo; etc.

Los dos cuentos que completan esta parte ("Contar un cuento" y "Él y el otro") continúan lógicamente esta línea de la imposible verificación de lo narrado. La única realidad de la historia que se cuenta es la de ser contada, por lo que su ficción o su verdad son equivalentes.

El grupo final, BORRADOR DE UN INFORME, no introduce ningún texto nuevo, sino que redistribuye cuentos publicados con 
anterioridad, colocando como apertura "Borrador de un informe". Este cuento se propone como paradigma de los siguientes ("Encuentro con el traidor", "El baldío", "El aserradero", "La flecha y la manzana", "El pájaro mosca", "La rebelión"): todos pueden ser considerados como borradores de un informe, que seguirá persiguiendo su forma definitiva sin alcanzarla jamás, porque la distancia entre la apariencia y el ser no se puede colmar. La verdad no tiene verificación posible en la palabra. No la tiene en el monólogo que rememora para sí mismo, o para un interlocutor aparente (como en la primera parte); ni en la narración de quien lo constituye en tanto que literatura (como en la segunda); ni en estas escrituras disolventes.

La verdad de la memoria tal vez pueda buscarse en el esquema que va completándose de cuento en cuento, a través de recurrencias, alusiones, improvisos reconocimientos. Una serie de notaciones permite establecer, por ejemplo, la identidad del narrador de "Nonato". En "Bajo el puente" se dice que el maestro era el redoblante de la fiesta del Niño-de-cabellos-rojos (lo que por otra parte remite a "Niño-azoté", en Los pies sobre el agua), y el narrador de "Nonato" tiene como única compañía su tambor; el camino del maestro hacia la muerte está narrado con los mismo términos con que Nonato narra su búsqueda de los recuerdos; cuando el narrador de "Bajo el puente" sorprende al maestro hablando solo, descubrimos la situación en que es pronunciado el monólogo de "Nonato":

Adentro, el rumor del maestro leyendo en voz alta, o hablando solo. Un poco después, la voz carrasposa se quebró en la voz de un chico que hablaba a una mujer, como un chico malcriado puede hablar a su madre: resentido, porfiado, apenas con respeto (pp. 35-36).

Estos dos cuentos se colocan pues en relación de continuidad con "Moriencia" y "Cuerpo presente" - respectivamente apertura y cierre de la primera parte - dedicados a la reconstrucción de la muerte de Chepé Bolívar: el maestro, personaje de "Nonato" y "Bajo el puente", es definido en "Moriencia" como una especie de doble de Chepé:

... [usted] se acordará todavía lo parecidos que eran, a pesar de sus diferencias, el maestro y Chepé. Lo veíamos al uno reflejado en el otro, como formando una sola persona (p.12). 
Al velorio de "Cuerpo presente" asiste María Dominga Otazú, "la dueña de la casa pública" (p. 44) de quien el narrador recuerda un regalo, un cachorrito "que después fue el Chimbo" (p. 46), es decir el perro que en "Ración del león" corre el riesgo de ser entregado a las fieras; también los enanos del circo están presentes en el velorio. Un personaje anónimo de un cuento recupera su nombre en otro, o revela un rasgo oculto... Aunque no todos los claros se llenen mediante estas operaciones, es evidente que se trata de un mundo concluido y compacto, que no deja resquicios para la irrealidad ${ }^{15}$.

Los cuentos de la segunda parte se relacionan entre sí, según otro tipo de esquema. Si bien de manera no demasiado explícita, los tres están adjudicados a un mismo narrador, "el gordo" ("Contar un cuento", p. 63; "Él y el otro", p. 69). El gordo es definido en "Contar un cuento" como "un pianista en relâche" (p. 65); en "Juegos nocturnos" el narrador aclara que en ciertas ocasiones se sentaba "un rato al piano"' (p. 60). También el lenguaje, matizado por giros porteños, caracteriza los cuentos de la segunda parte, que contiene alusiones a las otras dos: en "Él y el otro" se narra la historia de pasión, de celos y de muerte protagonizada por los enanos del circo que en "Cuerpo presente" asisten al velorio de Chepé Bolívar; como ya hemos visto, también "El aserradero", colocado en la tercera parte, es absorbido por este cuento. Las referencias internas se multiplican en la tercera parte que además, por la presencia de María Dominga Otazú en "Borrador de un informe", remite a la primera ("Ración del león", "Cuerpo presente'), con la que se coloca en un mismo nivel de realidad.

${ }^{15}$ En la presentación del volumen, Roa Bastos aclara cómo estos cuentos "forman parte de un ciclo en curso que ha acabado por desbordar en una novela, aún inconclusa"' (p. 9). Todos estos aspectos sugieren una analogía con el tipo de universo textual que define la narrativa de García Márquez. También éste construye, a partir de la recurrencia de hechos y personajes, una propuesta de universo que va buscándose y completándose a sí mismo de cuento en cuento. Pero aunque allí también ese universo tenga sus raíces en lo extratextual, como ha demostrado la crítica, tiende a presentarse como autosuficiente y cerrado. Macondo es la medida de su propio espacio, aunque linde con geografías que nuestros mapas reconocen. Los claros en la narración no se pueden colmar: se trata de un mundo que, según las visiones de los personajes o las astucias del narrador, desdibuja sus contornos, fluctúa, escapa. Y ésa es precisamente su realidad: ser inaferrable. (Sobre la función de las recurrencias y vacíos de narración en García Márquez, remito a mi trabajo "Las técnicas del sentido en los cuentos de Gabriel García Márquez'), ReoIb, 1984, núms. $128 / 129$. 
Así pues, el primer y tercer grupo de cuentos resultan homogéneos por el estatuto de realidad de los hechos, mientras el segundo retoma la realidad del primero y el tercero, transformándola en materia de una narración: la vuelve literatura. El narrador de este grupo, a diferencia del "yo" del primero, que se interroga sobre su propia experiencia, o sobre la de los seres cercanos, no tiene ninguna participación en los acontecimientos que narra, si no es a través de su palabra. Su función es más bien la de proponer una interpretación sobre el sentido de los hechos. Función ambigua si se quiere, pero de todos modos inevitable: si por una parte la palabra no puede corresponder a la realidad, por la otra sólo en la palabra la realidad se vuelve cognoscible.

En relación con la creciente complejidad de las líneas organizadoras de los conjuntos pueden analizarse ciertos aspectos de estructuración del cuento, como el uso de la primera persona. Ésta empieza a adquirir particular relevancia a partir de Los pies sobre el agua, o sea desde que empieza a definirse con claridad el eje de la búsqueda de una memoria. Lo importante, de todos modos, no es la riqueza técnica cada vez mayor, sino la elección de un módulo que de por sí connota la incertidumbre sobre lo narrado: el yo no puede sino ofrecer una visión parcial de la realidad - la que conoce, o quiere hacer conocer.

Se trata en algunos casos de un yo infantil (como el de la primera parte de Moriencia), cuyo conocimiento del mundo está limitado por una perspectiva reducida; en otros (como en la segunda parte), diferentes voces en primera persona se superponen a la del narrador de los hechos multiplicando las incertidumbres. El último grupo de cuentos de Moriencia, más heterogéneo desde el punto de vista de la voz narrativa, está encerrado por dos testimonios en primera persona: el de "Borrador de un informe" y el de "La rebelión", escritos, el primero para ocultar una verdad, y el segundo para restituirla.

A esta construcción de un yo reminiscente, se va sumando la creciente complejidad de los enganches que unen unos cuentos a otros, enmarañándolos y constituyendo un mundo derivado de la memoria. Pero que, paradójicamente, puede prescindir de ella, en la medida en que no se limita a la memoria de ningún individuo en particular: está en la experiencia de todos los personajes que forman parte de ese único mundo.

Creo que allí se genera - no como factor puramente estético, sino funcional- la insistencia en los finales truncos, o de todos modos no completamente resolutorios, o apenas alusivos. Es porque, idealmente, la historia ha de irse completando en otra parte, 
en otro cuento que ya leímos, o que debe aún ser escrito. Así María Dominga Otazú, la "rea del Guayrá", ha muerto en "Borrador de un informe"' (El baldío); pero volvemos a encontrarla entre los asistentes al velorio de Chepé Bolívar en "Cuerpo presente" (Moriencia). La reproposición de "Borrador..." en la tercera parte de este conjunto restituye a la historia su orden cronológico.

La posibilidad de trazar una línea cronológica no indica, sin embargo, que la construcción de la memoria global sea progresiva. La totalidad se constituye por acumulación de informaciones, ampliando círculos concéntricos que ilustran un mismo tema, y cuya organización se ve iluminada desde distintos ánglos, según el lugar que ocupen en los conjuntos sucesivos.

La constante reproposición de "La rebelión" ilustra claramente esta búsqueda del sentido: si en El baldio y Los pies sobre el agua resulta conectado sólo marginalmente a los ejes organizadores, en Moriencia, como cierre del conjunto, encuentra finalmente su lugar significativo. Este cuento narra el proceso de un levantamiento, cuyo sujeto fundamental son las mujeres:

Nadie sabe en qué momento han comenzado a reunirse, ni cómo han podido atravesar los cordones de tropas. Lo más extraño de todo es por qué descuido, respeto e indiferencia han dejado reunirse a esas mujeres. Justo ahora y allí, en esta amenaza de catástrofe que pesa sobre la ciudad desde la madrugada (p. 157).

La apertura del cuento, en presente, renueva en cada acto de lectura - "ahora y allí" - la actualidad de la rebelión. Ante la eterna repetición de los cuartelazos, "estos cólicos endémicos del régimen" (p. 157), la repetición que sugieren las estructuras lingüísticas es de otro tipo: la respuesta de la rebelión. Llegado el caso, ésta puede extenderse como por un contagio: la protesta de las mujeres, la deserción de los soldados, la toma de armas por parte de los civiles, que juntos emprenden "esta marcha victoriosa", (p. 169).

Que tan victoriosa no habrá sido, si quien escribe este testimonio lo hace desde la cárcel, ante la sorpresa de sus compañeros que no comprenden tanta insistencia (y si otros datos textuales connotan de irrealidad la manifestación de las mujeres, descrita como un "transparente hacinamiento", p. 163). Pero la insistencia nace tal vez de la voluntad de demostrar que la esperanza es posible. Por eso, a pesar del ambiguo final, "La rebelión" niega, con una nota de rotura hacia el futuro, la reiterada tiniebla de 
la memoria, el empantanamiento de la historia en una violencia que viene tejiéndose sin pausa desde El trueno entre las hojas. Creo que en este sentido, "La rebelión" puede leerse como una cifra de optimismo final que no se doblega. Si los cuentos de Roa Bastos urden en general un mundo de catástrofes, visto por los personajes como un destino ineludible, las mujeres de "La rebelión", como la Gretchen de "Carpincheros", son capaces de torcerlo -o por lo menos lo intentan- imponiéndose a la realidad:

...por más que escarbe en mis recuerdos, esto que veo allí abajo no se parece a nada conocido, y es que en el recuerdo y tal vez también en la esperanza las cosas no se parecen más que a sí mismas. Allí está pasando algo extraño, "Algo extraño como la verdad", dijo una vez Muleque (p. 164).

Asistimos pues a la construcción de un sistema que, gracias tanto a sus oscuridades y tanteos cuanto a sus más precisas y meditadas arquitecturas, va delineando su sentido profundo: la búsqueda, a través de los recuerdos individuales, de la memoria de una nación. Esta búsqueda afanosa, obsesión constante de la literatura paraguaya ${ }^{16}$, se desdobla aquí en otra indagación: la que trata de definir la naturaleza del acto narrativo. En este tipo de pregunta puede identificarse la función del deslizamiento cronológico que en la segunda parte de Moriencia nos hace asistir primero (en "Contar un cuento") a la muerte del narrador y, en el cuento siguiente ("Él y el otro"), a una de sus narraciones: no importa la identidad de quien formula la palabra, sino el eco de la palabra formulada. Todo narrador puede a su vez ser narrado, independientemente de su realidad. Alguien - el lectorhabrá de colocar todos estos acontecimientos en una línea lógica y cronológica, habrá de completar los claros, àe establecer las relaciones implícitas o arteramente ocultadas, restituyendo a la historia su verdad y su sentido.

El desorden y los vacíos se vuelven signos de una gran memoria que trata de reconstruir, con sus medios precarios, una gran unidad. La actividad del lector - sobre la que escritores y críticos actuales han insistido hasta la exasperación ${ }^{17}$ - adquiere aquí un

${ }^{16}$ Véanse al respecto, A. ROA BASTOS, "Escritura y liberación. . ." y A. L. AldanA, op. cit., pp. 18-19.

${ }_{17}$ Pienso, por ejemplo, en la definición del "lector hembra" en CORTÁZAR (Rayuela, Sudamericana, Buenos Aires, 1965, p. 500; también 62. Modelo 
valor que podríamos llamar político; el mismo que posteriormente llevará a Roa Bastos a formular su teoría del escritor como simple compilador. El escritor no crea, sino que reúne y ordena materiales preexistentes, cuyo autor último es el pueblo; el lector, en una tarea simétrica, los actualiza, asumiendo las contradicciones y la ambigüedad de la historia ${ }^{18}$.

Las relaciones entre los textos de un conjunto pueden establecerse según reglas muy sutiles, a veces rayanas en la paradoja, porque no derivan necesariamente de la escritura, sino de la elaboración de la lectura, que traza ejes como los que he tratado de poner de relieve en estas páginas (lo que, por otra parte, no niega la posibilidad de identificación de otros ejes por parte de otras lecturas).

No se trata con esto de establecer forzosamente para cada conjunto la condición de macrotexto pero se hace manifiesta, de todos modos, la imposibilidad de lecturas independientes: el texto alcanza la significación sólo por la interacción con los otros textos. No podríamos, por ejemplo, hablar de "Él y el otro" como de una reflexión sobre la escritura en relación a la realidad, si no estuviera contiguo a otros dos cuentos en los que el narrador es siempre "el gordo", y si un poco más allá "El aserradero" no propusiera una comparación, no entre dos tipos de versiones de una realidad, sino entre dos realidades situadas en distintos niveles.

Tal vez, al fin de cuentas, no sea necesario poner una etiqueta (macrotexto, sistema textual) a este tipo de relaciones. Lo necesario es reconocerlas en su funcionalidad, transformarlas en sugerencias de lectura. En el caso particular de los textos analizados, la implicación (cada texto representa una parte de un mismo universo) y la sustitución (el universo dado como "real" en un texto es asumido por otro como materia de "literatura") actúan como fuerzas constitutivas de la memoria. El recuerdo individual puede ser incompleto, o falaz, pero una verdad existe: la que se reconstruye en la memoria colectiva.

Así pues, si una frase de "Cuerpo presente" me sirvió de epígrafe para estas reflexiones, una de "El y el otro" puede ser utilizada para cerrarlas, ya que nos ofrece la más certera definición

para armar, Sudamericana, Buenos Aires, 1968, p. 97) o en el volumen que U. ECO dedica al problema de la "cooperación" del lector en los textos narrativos (Lector in fabula, Bompiani, Milano, 1979).

18 Sobre el concepto de la escritura como "compilación", véase A. ROA BASTOS, "Réflexion autocritique à propos de Moi, le Suprême, du point de vue socio-linguistique et idéologique. Condition du narrateur', CCLL, 136-150. 
de esto, que he llamado el sistema textual de los cuentos de Augusto Roa Bastos:

...y eso es lo que estoy tatando de decirles que hay ciertos seres ligados inexorablemente como si hubiera entre ellos un cordón umbilical y todo lo que sucede no sirve sino para juntarlos más porque el trozo de nervio placentario se va acortando y sólo la muerte o tal vez ni eso puede cortarlo (pp. 73-74).

ROSALBA CAMPRA

Università degli Studi di Roma "La Sapienza"

\section{APÉNDICE}

1953. El trueno entre las hojas

Carpincheros

El viejo señor obispo

El ojo de la muerte

Mano Cruel

Audiencia privada

La excavación

Cigarrillos Máuser

Regreso

Galopa en dos tiempos

El karuguá

Pirulí

Esos rostros oscuros

La rogativa

La gran solución

El prisionero

La tumba viva

El trueno entre las hojas

1966. El baldío

El baldío

Contar un cuento

Encuentro con el traidor

La rebelión

El aserradero

Borrador de un informe

La tijera

Hermanos

La flecha y la manzana

Éby el otro

El pájaro mosca 
1967. Los pies sobre el agua

Nonato

Macario

Borrador de un informe

El karuguá

Ajuste de cuentas

La rebelión

Hogar

Niño-azoté

La gran solución

La excavación

1967. Madera quemada

Kurupí

Bajo el puente

Niño-azoté

El baldío

Él y el otro

$\mathrm{El}$ viejo señor obispo

La excavación

El prisionero

La tumba viva

El trueno entre las hojas

1969. Moriencia

I: "Moriencia"

Moriencia

Nonato

Bajo el puente

Ración del león

Cuerpo presente

II: "Juegos nocturnos"

Juegos nocturnos

Contar un cuento

Él y el otro

III: "Borrador de un informe"

Borrador de un informe

Encuentro con el traidor

El baldío

El aserradero

La flecha y la manzana

El pájaro mosca

La rebelión. 